\title{
Observatorios Web y portales del conocimiento
}

\author{
Juan Voutssás M. *
}

Artículo recibido:

7 de octubre de 2011.

Artículo aceptado:

5 de junio de 2012.

\section{RESUMEN}

Este documento pretende analizar y establecer la naturaleza, características y elementos de las publicaciones Web denominadas "Observatorios Web" y "Portales del Conocimiento" de forma integral y práctica, sobre todo los aspectos que inciden en el desarrollo e implementación exitosa de una publicación digital de estos tipos construida en función de los objetivos básicos de cualquier institución en el medio mexicano. Parte de esta investigación se estudió teóricamente en la literatura; otra parte se realizó observando una serie de características y atributos visibles en sitios Web y portales existentes y finalmente otra parte se desarrolló a través de la selección de una "institución tipo" donde se realizó un estudio de caso analizando al interior de la misma el contexto, recursos, necesidades, etc. que ayudasen a es-

* Instituto de Investigaciones Bibliotecológicas y de la Información de la UNAM, México.voutssas@unam.mx

INVESTIGACIÓN BiBLIOTECOLÓGICA, Vol. 26, Núm. 57, mayo/agosto, 2012, México, ISSN: 0187-358X. pp. 131-175 
tablecer de forma integral y sobre todo práctica todos los elementos que inciden en el desarrollo e implementación exitosa de un publicación Web del tipo "Portal del Conocimiento". El estudio contempla los aspectos editoriales, tecnológicos, bibliotecológicos, administrativo-financieros y legales.

Palabras clave: Publicaciones digitales; Conceptualización, diseño y desarrollo de observatorios Web y portales del conocimiento; Observatorios virtuales; aspectos editoriales, tecnológicos, legales y bibliotecológicos.

\section{ABSTRACT}

\section{Web Observatories and Knowledge Portals}

Juan Voutssás M.

This paper analyzes thoroughly in theory and functionality the nature and components of the Web publishing types known as "Virtual" or "Web observatories" and "Knowledge Portals", mostly on those aspects which enhance their successful construction while being developed by an institution. Therefore, part of this research was built from the current literature; a second part observing those aspects from these types of sites visible in the cyberspace, and finally, working a study case in an institution analyzing its context, necessities, resources, etc., in a thoroughly manner to discover all the fine elements that boost a successful development of such a site. The study range the publishing, technical, library, managing and legal aspects of construction.

Keywords: Web portals; Knowledge portals; Concept, design and development of virtual observatories and knowledge portals.

\section{INTRODUCCIÓN}


disciplina, los cuales provienen de múltiples organizaciones. Por lo mismo es perfectamente lógico y natural que contemplen el desarrollo de un portal Web al efecto para dar salida a esa información en forma digital vía la red mundial. En una gran mayoría de casos, estas organizaciones han realizado ya este tipo de proyectos ajustándose a paradigmas "típicos" bajo una óptica estrictamente computacional como si fuese un sitio Web más; desafortunadamente, estas visiones parciales inciden negativamente en el desarrollo y éxito de este tipo de publicaciones. Entre los tipos actuales de sitios Web sobresalen dos para los propósitos enunciados; los denominados "observatorios virtuales" y los "portales del conocimiento". La construcción de forma profesional de cualquiera de estas publicaciones Web conlleva un enfoque más holístico, una planeación detallada, una visión e integración de variados aspectos transdisciplinarios que influyen en su desarrollo adecuado y consecuente éxito: aspectos editoriales, tecnológicos, bibliotecológicos, administrativo-finacieros y finalmente aspectos legales.

La correcta inclusión, balance e implementación de todos estos aspectos al momento de conceptualizar, diseñar y construir un "observatorio Web" o un "portal del conocimiento" en una cierta institución maximizan su eventual aceptación y éxito por parte de la comunidad destino correspondiente. Por lo mismo es pertinente establecer cuáles son las características que definen a las publicaciones de esta naturaleza, cuáles sus semejanzas y diferencias, cuáles las diferentes opciones para construirla, cuáles son los atributos que buscan en estos sitios las diversas comunidades que acceden a ellas, cuáles son los aspectos editoriales y cuáles son aquellos de Tecnologías de Información y Comunicaciones -TIC- que deben cuidarse y finalmente cuáles son aquellos aspectos adicionales a los tecnológicos que deben ser contemplados: legales, económicos, etcétera.

Para contestar estas interrogantes se ha investigado teóricamente en la literatura sobre el tema; otra parte se realizó estudiando y comparando una serie de características y atributos relevantes y comunes en portales Web existentes y que son de estos tipos. Finalmente se seleccionó además una "institución tipo" para realizar un estudio de caso y observar al interior de la misma la serie de atributos, necesidades y contexto propios que ayuden a establecer, confirmar y validar de forma práctica todos los elementos que inciden en el desarrollo e implementación exitosa del "observatorio virtual" o "portal del conocimiento" en formato digital, construido en función de los objetivos básicos de una institución ad hoc en el medio mexicano.

De inicio es necesario ubicar a las publicaciones Web dentro del contexto de las publicaciones digitales en general, ya que tienen diferentes naturalezas $\mathrm{y}$ variantes que es pertinente establecer. 
En términos históricos, las publicaciones digitales provienen de los tradicionales formatos de edición de materiales sobre soportes tradicionales, pero adaptados a las Tecnologías de Información y Comunicaciones. En un principio eran simples versiones electrónicas muy semejantes a sus originales en aquellos soportes. Así vimos nacer libros electrónicos, revistas electrónicas, música digital, repositorios electrónicos de fotografías, mapas, cartas, tablas, partituras, etc., todos los cuales originalmente tenían gran parecido con su predecesor sobre soporte tradicional. Hoy en día todos estos conceptos de publicaciones digitales se han ido sofisticando cada vez más y ya se hace evidente que estas nuevas versiones han ido tomando su propia personalidad y naturaleza mucho más allá de las simples copias sobre soportes electrónicos. Así, hoy en día los conceptos de libro electrónico o e-book, revista electrónica en sus distintas variantes: e-journal, e-magazine, e-newsletter; boletines, gacetas, anuarios, etc. en la actualidad van mucho más allá de la simple copia en un soporte digital. Los mapas y aplicaciones de la geomática moderna rebasan el simple despliegue de un mapa sobre un papel o una pantalla, y así sucesivamente.

Además de las anteriores, el desarrollo acelerado y la globalización de las TIC permitió la creación y desarrollo de las redes de comunicación mundiales, en especial la World Wide Web. Con su advenimiento y auge, la publicación de contenidos sobre la Web -o simplemente "publicación Web"- se consolidó como una más de las modalidades de publicaciones digitales de esta época, la cual ha devenido en la última década en una explosión documental y de contenidos.

Una publicación Web es por tanto cualquier publicación de materiales documentales aprovechando la infraestructura, naturaleza y características de la World Wide Web, en especial el formato $\mathrm{HTML}^{1}$ y los navegadores o browsers que permiten su uso. Su forma más simple es el "sitio Web"; esto es, un conjunto de páginas Web en formato HTML y archivos electrónicos en otros formatos organizados jerárquicamente, localizable universalmente por medio de un nombre de dominio y/o una dirección en Internet específicos, y legible gracias a un tipo de programa llamado "navegador". Son construcciones muy sencillas desde el punto de vista estructural e informático utilizados individuos y por organizaciones públicas y privadas para dar a conocer cierta información, facilitar un cierto trámite, divulgar un tema, etc. El sitio Web puede contener a su vez alguna o algunas de las otras publicaciones digitales -e-libros, e-revistas, etc.- entremezclando además formatos multimedia textos, imágenes, sonido, video, etc.-. Por lo general pertenece y trata acerca de una sola persona, empresa, organización o tema. 
La modalidad de portal Web es algo más compleja: un portal tiene un nivel superior en jerarquía al de un simple sitio Web; el portal es trans y multinstitucional, y tiene por lo general -además de sus contenidos propiosservicios agregados tales como búsqueda especializada, compra, enlaces, comunidades de interés, contextos personalizados para los usuarios, foros de discusión, etc., y se entiende como la ruta o acceso primigenio para llegar a otros sitios Web específicos. El portal Web tiene exactamente la misma acepción que en la arquitectura: "zaguán o primera pieza de la casa, por donde se entra a las demás, y en la cual está la puerta principal” o "en una casa de vecinos, pieza inmediata a la puerta de entrada que sirve de paso para acceder a las distintas viviendas". Por lo mismo, el portal tiende a contener información que proviene de varias instituciones, varios lugares de origen y múltiples sitios Web permitiendo el acceso a todos ellos desde un punto principal o preferido; cuando están sólidamente construidos tienen gran reconocimiento en la red por el gran poder de influencia que ejercen sobre grandes comunidades.

Los portales Web se clasifican en tres tipos básicos: portales "horizontales", portales "verticales" y portales "híbridos" o "diagonales". Los primeros son aquellos de propósito general, cuyo objetivo es llegar al mayor número posible de personas con un amplio rango de informaciones y servicios, sin especializarse en nada propiamente; por ejemplo Yahoo, Altavista, AOL, etc. Los verticales son aquellos que tienen una temática más puntual y buscan un público muy específico, tratando de brindar contenidos detallados y especializados sobre su tema: pintura, salud, deportes, música, historia, finanzas, etcétera. Un portal vertical es por tanto

[...] un punto de entrada especializado a un nicho específico de mercado o industria, a un área temática o de interés. También se le conoce como 'vortal' -contracción de 'vertical portal' (Business Dictionary, 2011).

Finalmente los portales híbridos son aquellos portales que desean mezclar características de los dos anteriores: llegar a un amplio espectro de usuarios, pero conservando una temática específica ofreciendo contenidos sobre el tema de diversas naturalezas, alcances, profundidad y variedades. Normalmente integran ya elementos provenientes de las redes sociales.

Esto es natural, dado que una de las características de la Web actual es el fenómeno "Web 2.0" cuyos atributos principales son la interactividad y la participación colaborativa o social. A raíz de este concepto se han creado en los últimos años una serie de "publicaciones Web" en este medio digital con perfiles y características inéditas en medios anteriores y altos niveles de 
especificidad: los "blogs", los “wikis", los “enlaces sindicados (RSS)" son sólo algunos ejemplos de este tipo de nuevas publicaciones digitales. Entre éstas, se incluye también el reciente desarrollo de una modalidad conocida como "observatorio virtual" u "observatorio Web".

\section{LOS “OBSERVATORIOS VIRTUALES” U “OBSERVATORIOS WEB”}

El observatorio tiene una característica muy especial e interesante: es a la vez publicación y acervo documental multimedia especializado, como cualquier portal Web. Pero además este "observatorio Web" consiste en una colección de archivos de datos e información organizados, aplicaciones y herramientas de programación, servicios, especialistas y espacios de red social agregados en un sitio Web donde con ayuda de esos elementos de interactividad, trabajo colaborativo y red social utilizan la Internet -en especial la Web- para construir un ambiente virtual de creación, búsqueda y divulgación de conocimiento acerca de un tema específico. El concepto, por tanto, va más allá del simple "sitio Web” y todavía más allá del "portal Web”. De la misma forma que un observatorio en la vida real está conformado por un conjunto de expertos y de telescopios, cada uno con una colección particular de instrumentos astronómicos, al "observatorio virtual" se agregan una serie de especialistas, dispositivos, herramientas, datos, información, asesoría, etc., pero integrados en un sólo lugar de manera coherente, sistemática y ordenada, con el propósito de poder crear un espacio integrado que propicie la creación, acumulación, búsqueda, intercambio, proceso y divulgación, etc., de datos e información acerca de una temática preestablecida con miras a la creación de un espacio de conocimiento alimentado por una comunidad relativamente abierta y colaborativa y puesto a disposición de públicos muy amplios. En un "observatorio virtual" se reúnen un conjunto de aplicaciones e información dispuestas de forma central donde no sólo se consulta material, sino el "estado del arte", comportamientos, corrientes y tendencias sobre la investigación y desarrollo del conocimiento sobre algún tema, y por tanto permiten la interacción en un público tan abierto que lo mismo sirve al observador ocasional como al analista o al experto. La idea rectora de la creación de un observatorio virtual es una suerte de "curaduría digital" de los elementos involucrados, de tal forma que bajo este concepto el todo resulte mayor que la simple suma de las partes.

Precisamente por esta última característica el observatorio no puede ser creado como una simple agregación de bancos de datos, catálogos, publicaciones, etc.: tal caso sigue siendo un portal Web a secas. El observatorio debe 
obedecer a ciertos principios de método que den orden y concierto para de esa forma poder llegar a ser lo que se pretende como una publicación de la "Web 2.0" en toda su esencia.

Las características fundamentales que se han de contemplar para la creación de un observatorio virtual son (Castañeda, 2006):

- Ampliar el espectro de observación, considerando el acceso no restringido de espacio y tiempo que brinda la Web.

- Incorporar información novedosa, a partir de un fenómeno o concepto específico a examinar, y cuyas temáticas giren alrededor del mismo. Se dispone de material de forma catalogada y distribuida en los distintos espacios y rubros organizados con información diaria, periódica o de consulta especializada. Lo anterior se lleva a cabo mediante esquemas de navegación transversal, mecanismos de almacenamiento y servicios de búsqueda avanzada.

- Favorecer el conocimiento, a partir de la creación y desarrollo de comunidades virtuales y redes más amplias de especialización para la aplicación, divulgación y construcción del mismo, mediante la activación de canales de comunicación, mensajería instantánea y otros más.

- Enriquecer los contenidos y su actividad dentro del observatorio mediante un Comité de Expertos, llamado también "Comité Editorial", que tiene como tarea fundamental garantizar la calidad de los contenidos al ofrecer información selecta y trascendente, para que en conjunto con la comunidad participante se ponga al alcance de investigadores, líderes de opinión y usuarios finales.

Para entender bien estos conceptos, nomenclaturas y características, es útil partir de su evolución.

\section{ANTECEDENTES Y DEFINICIÓN}

El primer "Observatorio Virtual" es una iniciativa internacional impulsada desde el año 2002 por la Unión Astronómica Internacional (International Astronomical Union o IAU), la cual es una agrupación de las diferentes sociedades astronómicas nacionales y constituye un órgano de decisión internacional en el campo de proyectos conjuntos internacionales, entre otros objetivos. El proyecto, denominado IVOA -International Virtual Observatory Alliance- ha tenido como objetivo crear un entorno de investigación que garantizara tanto la interoperatividad entre los sistemas de información astronómica como 
una eficiente gestión y análisis de los grandes volúmenes de datos que dichos sistemas almacenan. Es un proyecto internacional que persigue el interconectar los archivos y las bases de datos de los telescopios terrestres y espaciales del planeta, junto con las herramientas de análisis y los servicios de computación para que formen un sistema integrado. A la fecha agrupa a diecinueve proyectos nacionales en donde miles de personas comparten datos, recursos humanos, equipos, etc. en un esfuerzo para la creación de un gran espacio compartido de conocimiento sobre la astronomía. (IVOA, 2007).

El IVOA se centra en el desarrollo de normas de trabajo conjuntas e impulsa su aplicación en beneficio de la comunidad astronómica mundial. Los grupos de trabajo se constituyen con miembros de los diferentes programas nacionales en el ámbito de los principales estándares de interoperabilidad y en donde las tecnologías tienen que ser definidas y acordadas. Los Grupos de Trabajo elaboran normas mediante un proceso de modelado a partir del "World Wide Web Consortium" en los que se elaboran borradores de las propuestas y finalmente las recomendaciones, que a su vez deben ser aprobadas por el Grupo de Trabajo de la Comisión al efecto del Observatorio Virtual y por la Unión Astronómica Internacional. El IVOA también tiene grupos de interés que discuten experiencias utilizando tecnologías y retroalimentando a su vez información a los Grupos de Trabajo.

La metodología desarrollada por este "observatorio virtual" ha sido un parteaguas y por lo mismo ha sido extendida a otros campos del conocimiento y adoptada por otras organizaciones como un medio para la creación de grandes espacios de conocimiento alrededor de una disciplina. El nombre ha permeado a estos nuevos esfuerzos quedándose ya como "observatorio virtual" u "observatorio Web" aunque la temática no tenga que ver con la astronomía.

Si bien los observatorios virtuales son creados hoy en día por todo tipo de instituciones y abarcan todo el espectro de disciplinas e intereses, en particular la administración pública ha encontrado en esta modalidad de portal un nicho que le ha parecido cómodo y adecuado para el estudio de problemáticas sociales, el planteamiento de fortalezas y debilidades de una cierta actividad, la observación, iniciativa, control, supervisión, transparencia, denuncia pública, etc. Esta aceptación obedece muy probablemente a la característica inherente al observatorio de contar con la mezcla de información variada a un amplio espectro de usuarios y colaboratividad social. El énfasis en las características descritas crea lo que se denomina en el medio como el "observatorio virtual social" o simplemente "observatorio social". 
Por su origen desde el observatorio astronómico algunos estudiosos del tema han establecido que

es posible suponer que los antecedentes de los actuales observatorios sociales se remonten [...] al desarrollo y empleo de los servicios de estadística -una ciencia matemática, aplicable a una gran variedad de disciplinas, consistente en coleccionar, analizar, interpretar y presentar datos- por parte de cuerpos administrativos a escala nacional (Albornoz y Herschmann, 2007).

\section{José Luis Maiorano establece que}

[...] los observatorios son una respuesta a la necesidad de realizar evaluaciones sobre un fenómeno determinado a través de organismos auxiliares, colegiados y de integración plural que deben facilitar el manejo de información a la opinión pública y propiciar la toma de acciones concretas por parte de las autoridades responsables (Maiorano, 2003).

En otros observatorios se añaden diferentes definiciones alrededor de un mismo concepto: un instrumento metodológico o foro de análisis y/u órgano técnico de análisis, diagnóstico y toma de decisiones. Todo lo anterior establece un cierto corte de "observatorio social" con las características enunciadas. Esta vertiente de los "observatorios sociales" es perfectamente válida y utilizable, pero no hay que confundirla con la vertiente principal de los observatorios virtuales: sitios que colectan y distribuyen información amplia sobre un tema a un público diverso, y sirven como punto de entrada a toda una serie de acervos y lugares alrededor de esa temática respondiendo a criterios de creación de una plataforma de estudios e investigación, centro de pensamiento y generación de conocimiento. Esta visión del observatorio es lo que Castañeda define como

[...] un sitio Web conformado por distintas herramientas que permiten crear un entorno informático para el acceso versátil a una red distribuida de archivos de información y datos a través de Internet. Su principal valor es el de constituirse como un sitio de reunión, que suma opiniones y colaboraciones relacionadas con un tema específico; no se trata de un foro de discusión, ni de un sitio de chat o de conversación, ni es una revista digital. El observatorio virtual retiene un conjunto de aplicaciones e información dispuestas de forma central donde no sólo se consulta material, sino comportamientos, corrientes y tendencias sobre la investigación y desarrollo del conocimiento sobre algún tema, que permiten la interacción en un público tan abierto que lo mismo sirve al observador como al analista o al experto (Castañeda, 2006). 
Las grandes ventajas de los observatorios virtuales pueden resumirse en:

- Aprovechan las ventajas inherentes de la red pudiendo interactuar en cualquier lugar y tiempo.

- La información es de variados tipos y formatos y proviene de diversas fuentes especializadas enriqueciendo así el acervo.

- Los recursos se actualizan con frecuencia y se incrementan en su variedad y oferta.

- Se puede crear una "masa crítica" de información, aplicaciones y recursos humanos que detone la generación de nuevos conocimientos más allá de la simple distribución.

- La naturaleza particular de estos observatorios fomenta e impulsa la aparición de comunidades especializadas o redes derivadas comunidades que retroalimentan la comunicación entre la plataforma y los asociados o usuarios.

- Por la amplitud de sus recursos, formatos y niveles, es útil tanto al observador casual como al experto o analista.

\section{Los “PORTALES DEL CONOCIMIENTO”}

Desde la década de los setentas se empezaron a sentar las bases de lo que sería conocido como "las organizaciones de aprendizaje"; es decir, empresas $\mathrm{u}$ organizaciones que consideraban el conocimiento como un activo valioso de la organización, vital para la competencia y desarrollo. En 1987, Bob Garratt describe las bases de lo que se había convertido ya en la "administración del conocimiento", continuadas por Karl Wiig y que es conocido hoy en día como "gestión del conocimiento" (Garratt, 1987; Wiig, 1990). Ives, Torray y Gordon (1997) elaboraron una reseña de esta evolución y su naciente interacción con las tecnologías de información. De estas teorías surge lo que hoy es conocido como "portales del conocimiento".

En general y como sucede con muchos otros sitios Web, los "portales de conocimiento" no presentan una definición única y sus características se traslapan y se entrelazan con las de otros sitios semejantes. Por lo mismo, se observa en la literatura al respecto nombres como "sistemas de conocimiento", "portales de información empresarial", etc. o como es la tendencia actual, "portales de conocimiento". La definición de Bolisani (2008), si bien es genérica, describe suficientemente las capacidades que debe tener un portal de conocimiento. De aquí puede afirmarse que la función de un ambiente de administración del conocimiento, y en especial su portal, es el 
de comportarse como una infraestructura que soporte el ciclo de vida de la organización, proveyendo con esto todas las funcionalidades necesarias para adquirir, modelar, compartir, extraer y publicar conocimiento dentro de una organización.

El "portal de conocimiento" representa entonces el siguiente nivel de evolución de lo que originalmente fue el "portal empresarial". Un portal de conocimiento es un requisito básico para que hoy en día una empresa u organización se convierta en una organización de aprendizaje. Provee todas las características que los miembros de la organización necesitan para que accedan, analicen y utilicen el conocimiento almacenado para generar nuevo conocimiento, además de aportar las nuevas experiencias de su actividad en la solución de problemas comunes.

Por su naturaleza, un portal de conocimiento permite almacenar información ya analizada, filtrada y procesada -conocimiento- para poder utilizarlo en otro momento y lugar distantes al de la creación de dicha herramienta. En la actualidad, las organizaciones hacen uso de dichos portales con la finalidad de que sus empleados o miembros puedan recurrir a información necesaria de manera oportuna y eficaz, lo que les permite resolver problemas con alta productividad. La información y la inteligencia organizacional ayudan a desarrollar los portales de conocimiento debido a que, mediante su uso interrelacionado al interior de la organización, permite encauzar, evaluar, modificar y controlar de forma muy activa todo el conocimiento adquirido por la organización. Además, la retroalimentación oportuna, frecuente y eficaz del conocimiento de la organización le permite a la misma estar preparada para la competencia adecuada que actualmente exige el mercado o entorno globalizado.

Los portales de conocimiento son del tipo de portal vertical y por lo mismo -al igual que los observatorios- se especializan en algún tema específico para ofrecer su cobertura profunda y así dirigirse a una comunidad especial de usuarios. Ofrecen un punto primordial y destacado de acceso personalizado a información relevante para permitir formación de opinión, toma de decisiones, capacitación y entendimiento sobre un tema. Como todo portal, estos sitios -además de apoyar la generación, captura, distribución e intercambio de conocimiento de las organizaciones- incluyen funciones de valor agregado tales como búsqueda especializada, compra, enlaces, comunidades de interés, contextos personalizados para los usuarios, foros de discusión, entre otras.

Como ha podido observarse, existen varias categorías, naturalezas y niveles de las publicaciones digitales: por las variedades de su presentación, por el tipo o modalidad de las mismas, por la temática, tipo de acceso y objetivos 
que las generan, etc. Hemos establecido sus variantes y distinguido y definido entre ellas a las publicaciones Web y particularizado a los denominados "sitios Web", "portales", "observatorios virtuales" y "portales del conocimiento". Ello nos permite entenderlos y de este entendimiento proceder a su planeación y desarrollo. Como ha podido establecerse también, los "observatorios virtuales" y los "portales del conocimiento" son herramientas informáticas que-no siendo idénticas-comparten muchos elementos comunes.

Como es objetivo de este documento permitir a una institución comprender de forma práctica tanto la naturaleza y perfil de un portal de alguno de estos tipos como todos sus elementos básicos y complementarios para finalmente permitirle emprender la construcción rápida y eficiente de una publicación de esta naturaleza con un diseño profesional y holístico, se consideró conveniente, para poder ilustrar de mejor manera los diferentes aspectos involucrados, seleccionar una "institución tipo" o ejemplo con un perfil adecuado para el desarrollo de un portal que ejemplificara los diversos aspectos de construcción de un portal de estas características como un caso práctico. En este caso, la "institución tipo" es la AMIJ -Asociación Mexicana de Impartidores de Justicia, A.C.-. Para el estudio y construcción, se consideró también pertinente dividir el proyecto en cinco apartados o aspectos a desarrollar: aspectos editoriales, tecnológicos, bibliotecológicos, administrativofinancieros y finalmente aspectos legales.

\section{Contexto DE LA INSTITUCión TIPO}

La Asociación Mexicana de Impartidores de Justicia -AMIJ- es una entidad que agrupa a jueces, magistrados y ministros como representantes de los diversos órganos encargados de impartir justicia en el país, tanto a los que pertenecen al poder judicial como a los de naturaleza administrativa en los diferentes ámbitos de su competencia. Sus antecedentes derivan del sistema nacional de impartidores de justicia, específicamente de la Declaración de Jurica del 2005, hecha por los miembros de la Suprema Corte de Justicia de la Nación, el Poder Judicial de la Federación, los Poderes Judiciales de las entidades federativas, el Tribunal Federal de Justicia Fiscal y Administrativa, el Tribunal Superior Agrario, la Junta Federal de Conciliación y Arbitraje, los Tribunales Electorales y de lo Contencioso Administrativo, las Juntas Locales de Conciliación y Arbitraje, y los Tribunales Federal y Locales de Conciliación y Arbitraje. Así, en abril de 2007 en la sede principal de la Suprema Corte de Justicia de la Nación se constituyó la AMIJ en forma de una asociación civil. 
Su finalidad es fomentar el sistema de impartición de justicia que requiere el país, a través de la unificación de esfuerzos para la elaboración de una agenda judicial que incluya políticas, programas y acciones de diversa naturaleza encaminadas a lograr una reforma judicial exitosa, y su objetivo general es la consolidación de las capacidades institucionales de los órganos de impartición de justicia en México.

Las líneas de trabajo de la Asociación se integran en cinco estrategias con sus respectivas acciones, las cuales están dirigidas a los órganos de impartición de justicia, basadas en las declaratorias y conclusiones producto de las diferentes reuniones que han llevado a cabo sus miembros: 1. Gobierno judicial, orientada al fortalecimiento de la función de gobierno y administración; 2. Procesos jurisdiccionales, establecida para lograr la eficiencia y eficacia de los procesos jurisdiccionales para resolver de manera oportuna los conflictos; 3. Capacitación, cultura judicial y transferencia de información con propósito de mejora de la calidad en la prestación de servicios de impartición de justicia; 4. Acceso a la justicia, con el objetivo de procurar que más sectores de la población tengan acceso a la impartición de justicia, especialmente aquellos en situación de vulnerabilidad; 5. Independencia y rendición de cuentas, con la finalidad de robustecer los mecanismos ya existentes en los órganos de impartición de justicia.

Es importante resaltar que la AMIJ puede desarrollar proyectos de mejora de la calidad de los servicios de justicia que distintos órganos han implementado; de hecho, ya ha desarrollado varios de este tipo. Por su propia misión la AMIJ tiene la misión de fungir como un espacio de diálogo, consulta y análisis de aspectos relevantes en su campo y de crear, publicar y difundir material e información a propósito de sus temáticas. Dado que tiene la misión y la vocación, además de contar ya con la madurez y el prestigio institucional, la viabilidad organizacional, la infraestructura y la "masa crítica" para poder dar salida a una serie de proyectos documentales, tanto propios como de otras instituciones miembros, ha iniciado los pasos para la creación de un "portal Web" alrededor de la ciencia jurídica, en particular sobre la temática de la impartición de justicia.

En la actualidad ni la AMIJ ni ninguna otra entidad semejante cuenta con una publicación de este tipo, pero cuenta sin duda con la infraestructura y características que la hacen ideal para objeto de un caso de estudio como el planteado.

Por su propia misión la AMIJ debe fomentar el sistema de impartición de justicia que requiere el país a través de la unificación de esfuerzos para la elaboración de una agenda judicial que incluya políticas, programas y acciones de diversa naturaleza encaminadas a lograr una reforma judicial exitosa, y 
cuyo objetivo general es la consolidación de las capacidades institucionales de los órganos de impartición de justicia en México. Como ha podido observarse, dentro de sus cinco líneas de trabajo rectoras, se encuentra la de

Impartir capacitación, cultura judicial y transferencia de información, con el propósito de la mejora de la calidad en la prestación de servicios de impartición de justicia.

Debido a ella, la AMIJ se ha dedicado desde su creación -entre otras actividades- a reunir, sistematizar y procesar la información relacionada con el ámbito judicial y difundirla a través de un anuario y otros medios de información eficientes, así como realizar actividades de difusión y vinculación de los trabajos relativos al tema producidos por el sistema de impartición de justicia. Si bien existen varios esfuerzos previos de la AMIJ en este sentido - en particular un sitio Web de ella- la asociación cuenta ya con la madurez tecnológica, el prestigio institucional, la viabilidad organizacional, la infraestructura y la "masa crítica" para poder dar salida de una forma más sistémica a una serie de materiales documentales, tanto propios como de otros colaboradores, vía una publicación Web específica.

\section{LOS DIFERENTES ASPECTOS}

\section{Aspectos editoriales}

Es de vital importancia que de inicio la institución editora reflexione profundamente en el objetivo toral de la publicación Web que pretende desarrollar: debe establecer claramente cuál es el perfil de la publicación a crear a partir de los objetivos de la institución con respecto al portal, diseñándolo a partir de la comunidad objetivo a la que se pretende llegar y de la cual se extraerán en un futuro potenciales contenidos. Este es el aspecto primordial que permite posteriormente definir las demás características del portal en función del objetivo institucional que se persigue. En esta sección -que es crucial para el desarrollo del portal- debe definirse la naturaleza y perfil del mismo, su conceptualización y diseño editorial; el tipo y corte del portal; tipo y variedad de lectores objetivo; tipo, calidad, variedad y alcance de los materiales que publicará; periodicidad, indización deseada, competidores, etc. Lo ideal es que el resultado del ejercicio en este aspecto se refleje en un documento de "política editorial" de la institución, la cual marque la pauta para desarrollo del portal tanto en el presente como en el futuro. 
Los elementos generales a considerar para el desarrollo de los aspectos editoriales son:

1) El análisis de las distintas modalidades de publicación Web: página Web, sitio Web, portal, observatorio virtual, portal del conocimiento, etc.

2) El estudio del perfil, requisitos y características técnicas, de contenido y presentación de los portales, los observatorios Web y los portales del conocimiento similares editados actualmente.

3) Definición por parte de la institución del tipo de portal que se va a producir entre las modalidades posibles: por lo general se utiliza alguna de las modalidades de portal "vertical" -vortal- o "híbrido". (En esta fase, la AMIJ estableció como premisa desde el principio que fuese un portal del conocimiento, el cual sería denominado "Portal del Conocimiento Jurídico").

4) El recabado de visiones y puntos de vista de los diversas instituciones socias o colaboradoras de la AMI que pudiesen aportar colecciones y servicios de valor agregado al portal acerca de sus preferencias y necesidades en lo respectivo a literatura jurídica y afín.

5) Establecimiento, alcance y cobertura y límite de las temáticas de portal que se incluirán en el sitio.

6) Establecimiento de la o las secciones que podrán existir en el portal; existencia y actualización de las secciones; criterios de elegibilidad para cada trabajo a ser incluido dentro de ellas; tipo y universo de fuentes del material y autores; canales y posibilidades viables de creación y/o consecución de materiales.

7) Establecimiento del tipo y variedad de lectores objetivo.

8) Tipo, variedad y alcance de los materiales que publicará; periodicidad e indexación deseada.

9) Establecimiento del grado de conexión e hipervínculo de las secciones del portal con otros puntos dentro del sitio Web de la AMIJ y de otras instituciones del sistema mexicano de impartición de justicia.

10) Establecimiento de versiones en línea: materiales documentales fijos (planos o estáticos) y/o elementos de actualización de versiones de artículos, elementos de "blog", "chat", "wikis" y "foros de discusión" con autores, usuarios, etcétera.

11) Establecimiento de las funciones de los responsables de la edición del portal y de sus partes.

12) Establecimiento del perfil comercial del portal si es que lo hubiese: puede ir desde el acceso abierto y gratuito, al acceso por suscripción o 
participación cobrada, o algún esquema mixto.

13) Finalmente, el establecimiento de una "Política Editorial" que guíe y norme a la publicación Web.

Para establecer lo anterior puede usarse una metodología que contemple algún o algunos de los elementos enumerados a continuación:

- La presentación de todos los diversos "tipos", "perfiles" y "secciones" con todas sus diversas modalidades, opciones y variantes posibles en portales digitales ante los directivos de la institución.

- El diseño y aplicación de una encuesta específica dentro de los sectores adecuados de la institución y otras instituciones afines.

- El estudio del perfil y características técnicas, de contenido y presentación de los portales similares editados actualmente. Establecer contra quién se compite y/o a quién se apunta como meta.

- Establecimiento de las características físicas de los materiales a recibir por sección: variedades, estructura, divisiones y orden; formato, extensión y criterios de elegibilidad. Estos criterios de elegibilidad para cada tipo de material a ser incluido dentro de cada sección pueden variar de una sección a otra, pero todos los tipos de materiales en todas las secciones deben tener establecidos esos criterios de elegibilidad.

- Algunos materiales (artículos, ensayos, editoriales, etc.) pueden estar sujetos a arbitraje -y deben ser aceptados- antes de poder ser publicados. Los criterios deben estar perfectamente preestablecidos y ser accesibles entre los potenciales árbitros y autores. Para ello, debe establecerse el perfil y número del cuerpo arbitral revisor pertinente a los criterios que deberá aplicar y los nombres de los expertos que conformarán ese grupo.

- Como sucede con toda publicación -Web o no- es altamente recomendable establecer al interior de la institución un "Consejo Editorial" que se encargue de analizar, discutir y en su caso aprobar los diversos aspectos editoriales presentados previamente con una visión estratégica y de largo alcance. Una vez aprobados es conveniente darles forma por medio de un documento de "Política Editorial" que una vez sancionado recoja todos los aspectos establecidos y sirva como marco para el desarrollo del portal. Es muy recomendable que el Consejo Editorial funcione permanentemente de forma tal que auxilie al titular de la institución y al editor del portal en el perfeccionamiento de políticas y líneas de acción, supervise y en su caso modifique la implementación y correcta operación del portal. Para ello es conveniente preestablecer las características y funciones del Consejo Editorial. 
Los elementos que un documento de "Política Editorial" establece son en general:

- Antecedentes y visión de la institución que crea el portal.

- Definición, concepto, visión y temática del portal Web.

- Tipo, corte y secciones del mismo.

- Criterios de elegibilidad de los trabajos a editar: tipos, estructura, requisitos, etcétera.

- Visión económica y financiera del portal.

- Conformación y funciones del Consejo Editorial.

- Política legal de la aceptación y distribución de los materiales publicados.

Es conveniente también el establecimiento claro de las funciones de un "editor" del portal encargado de gestionar todos los aspectos organizativos, administrativos y editoriales del portal y nombrar una persona con esta función expresa, ya sea como parte de la institución editora o como un consultor externo. Esta es una condición sumamente importante, ya que se requiere un profesional especializado en esta función para velar por el cumplimiento de la política editorial así como por la revisión, edición y publicación de los materiales, entre muchas otras tareas. La falta de esta función y/o de un profesional especializado y dedicado conduce con frecuencia al incumplimiento de tiempos y niveles de calidad del portal con su consecuente demérito y posterior desaparición.

A continuación se presenta el documento que fue elaborado como proyecto de "Política Editorial" a ser utilizada por el "Portal del Conocimiento Jurídico” de la AMIJ.

Politica Editorial del "Portal del Conocimiento Jurídico" de la AMIJ - Asociación Mexicana de Impartidores de Justicia, A.C.-

\section{Antecedentes}

Por su propia misión la AMIJ debe fomentar el sistema de impartición de justicia que requiere el país, a través de la unificación de esfuerzos para la elaboración de una agenda judicial que incluya políticas, programas y acciones de diversa naturaleza encaminadas a lograr una reforma judicial exitosa, cuyo objetivo general es la consolidación de las capacidades institucionales de los órganos de impartición de justicia en México. Dentro de sus cinco líneas de trabajo rectoras, se encuentra la de 
Impartir capacitación, cultura judicial y transferencia de información, con el propósito de la mejora de la calidad en la prestación de servicios de impartición de justicia.

Debido a ella, la AMIJ se ha dedicado desde su creación -entre otras actividades- a reunir y procesar la información relacionada con el ámbito judicial y difundirla a través de un anuario y otros medios de información eficientes, así como realizar las actividades de difusión y vinculación de los trabajos relativos al tema producidos por el sistema de impartición de justicia. Si bien existen varios esfuerzos previos de la AMIJ en este sentido, la asociación cuenta ya con la madurez tecnológica, el prestigio institucional, la viabilidad organizacional, la infraestructura y la "masa crítica" para poder dar salida de una forma más sistémica a una serie de materiales documentales, tanto propios como de otros colaboradores, vía una publicación Web.

Del análisis de las distintas modalidades de publicación Web: página Web, sitio Web, portal, observatorio, etc., se establece para este proyecto una mezcla de la modalidad de Portal del conocimiento en Web con la de Observatorio Web, que en este caso específico se denominará un "Portal del Conocimiento Jurídico". La razón principal de ello es que el portal debe convertirse en una herramienta fundamental para invitar a todos los usuarios de la comunidad afín a insertarse en un concepto de "Sociedad del Conocimiento" en el ámbito de la impartición de justicia, e ir más allá de un simple sitio Web. Bajo este principio,

[...] el simple acceso a las TIC y a las redes no pone a sus beneficiarios en un plano superior. Si las personas no pueden obtener de ello los mecanismos para propiciar el desarrollo de cada individuo informatizado y de su entorno social todo habrá sido en vano. Hay que ofrecer a cada persona la posibilidad de adquirir las competencias y los conocimientos necesarios para comprender, participar activamente y beneficiarse plenamente de la sociedad de la información y la economía del conocimiento; los miembros de esta sociedad deben poder estar informados y ser creativos. La utilización y despliegue de las TIC debe orientarse a la creación de beneficios en todos los ámbitos de la vida cotidiana.

Esta decisión se funda además en el hecho de que la AMIJ ya tiene un sitio Web idóneo para sus tareas operativas en el cual se había comenzado a ofrecer el material documental, de capacitación, informativo, etc.; pero dado que se desea hacer esto a gran escala y de acuerdo con los principios rectores enunciados, no resulta conveniente simplemente agrandar el sitio Web de la AMIJ e integrar ahí estos servicios de construcción y de entrega de servicios de 
información y conocimiento, sino crear un sitio específico al efecto el cual se complemente con el sitio Web de la AMIJ sin estorbarlo ni hipertrofiarlo. En este caso la modalidad de portal es obvia: un portal tiene un nivel superior en jerarquía al de un simple sitio Web, el cual suele ser institucional, es decir, contiene datos de una sola organización o grupo de ellas. El portal es trans y multinstitucional, tiene servicios agregados y se entiende como el punto primigenio de arranque para llegar a sitios Web específicos. Los ingredientes del observatorio virtual agregan el aspecto de buscar "un todo mayor que la suma de las partes" y el ingrediente de alta colaboración y uso de redes, en especial las sociales.

\section{Objetivos y visión}

Por lo mismo, el "Portal del Conocimiento Jurídico" debe ser un entorno informático para el acceso versátil a una red distribuida de archivos de información y datos, de herramientas de programación, de servicios de valor agregado, de contenidos, especialistas y espacios de red social agregados en un único sitio Web donde, con ayuda de esos elementos de interactividad, trabajo colaborativo, red social y uso de la Internet, en especial la Web, establezcan un ambiente de creación, acumulación, búsqueda, intercambio, proceso y divulgación de conocimiento acerca del tema de la impartición de justicia y temas afines. Su principal valor debe ser el de constituirse como un sitio de reunión, que sume opiniones y colaboraciones relacionadas con todos los temas relacionados a esta temática. No debe construirse simplemente como un blog, foro de discusión, chat o revista digital, aunque podrá contener estas modalidades. El portal contendrá un conjunto de aplicaciones e información orquestadas en forma central donde no sólo se consulte material, sino comportamientos, corrientes y tendencias sobre la investigación y desarrollo del conocimiento sobre su tema, y debe permitir la interacción en un público tan abierto que lo mismo sirva al observador como al analista o al experto. En su construcción se pretende que el todo sea mayor a la suma de las partes y con base en los principios de "gestión del conocimiento", "contenidos ricos" y de las redes sociales, debe fundarse sobre la colaboración y la interactividad y debe obedecer a ciertos principios de método que den orden y concierto central para de esa forma poder llegar a ser lo que pretende.

\section{Del portal}

La publicación electrónica o "Portal Web del Conocimiento Jurídico" de la AMIJ -Asociación Mexicana de Impartidores de Justicia, A.C.- es una publicación 
digital en-línea destinada a adquirir, modelar, compartir, extraer y divulgar servicios de información y conocimiento para la divulgación de toda una serie de materiales documentales, académicos, culturales, informativos y de capacitación así como difundir las actividades de difusión y vinculación de los trabajos relativos al tema producidos en el ámbito judicial por el sistema mexicano de impartición de justicia. Estos materiales estarán dirigidos a todas las instituciones y personas que conforman este sistema así como a otros interesados en él. Debe permitir encauzar, evaluar, modificar y controlar de forma muy activa todo el conocimiento adquirido por el sistema mexicano de impartición de justicia, además de la retroalimentación oportuna, frecuente y eficaz de este conocimiento. El Portal será construido bajo los principios de "Portal del Conocimiento" y de "Observatorio Web" a la vez y debe reflejar los objetivos y las líneas de trabajo de la AMIJ, en especial la de "Impartir capacitación, cultura judicial y transferencia de información, con el propósito de la mejora de la calidad en la prestación de servicios de impartición de justicia”.

En sintonía con la naturaleza propia de la AMIJ, el portal es una publicación sin fines de lucro cuya misión y perfil abarcarán una amplia variedad de colecciones y servicios de información a través de varias secciones que permitan acceder a la difusión y vinculación de los trabajos relativos al tema, producidos en el ámbito judicial por el sistema mexicano de impartición de justicia.

Dado que el principio de los "contenidos ricos" es uno de los ejes conductores de este proyecto, su diseño editorial no se basa en funciones o secciones como es tradicional en un portal, sino a partir de un núcleo basado en la conceptualización de las "colecciones" y los "servicios" que el sitio debe construir y ofrecer, integrando un tercer elemento específico importante por separado dada la naturaleza de la AMIJ: la "divulgación".

Se tratará que el sitio Web sea acumulativo en los materiales en los que esto sea pertinente, por lo que los lectores podrán encontrar tanto información actual como toda la retrospectiva. El sitio Web tendrá por nombre oficial "Portal del Conocimiento Jurídico". Se registrará el nombre de dominio "http://www ." a nombre de la AMIJ con sus posibles variantes mnemónicas. En corto plazo deberá contar con un buscador interno adecuado a sus propósitos y alcance. Se pretende desde su inicio que el portal cuente con servicios de valor añadido; entre ellos: alerta, diseminación selectiva de información "awareness internet services", enlaces sindicados de fuentes Web codificadas en XML (RSS), foros de discusión, podcasts, webcasts, etc. Además, y para garantizar su alto nivel de acuerdo con estándares internacionales, se emiten una serie de "Estándares técnicos obligatorios mínimos así 
como estándares deseables del sitio Web derivados de la Política Editorial". Estos estándares internacionales deben ser construidos desde el arranque.

El sitio Web publicará en lo posible sus documentos sobre la base de máxima divulgación y alcance posibles de los materiales; esto es, "acceso abierto" en su concepto más amplio, sin ningún cargo económico ni a los autores ni a los lectores; para ello, todos los materiales publicados que no estén en dominio público serán liberados bajo una licencia de uso de "ciertos derechos reservados" (licenciamiento tipo "Commons" Attribution Non-Comercial Share Alike 2.5 Unported, clave cc by-nc-sa), la que en esencia permitirá la descarga gratuita y libre de los materiales y la reutilización de los trabajos en otros sitios que también sean sin fines de lucro, permitiendo obras derivadas bajo el mismo tipo de licencia y por supuesto citando completa la fuente y autores. -Reconocimiento, No-Comercial, Compartir bajo la misma licencia, versión 2.5-. Los autores retendrán el derecho de publicar sus obras posteriormente en otros medios.

Como resultado de esta conceptualización básica proveniente de la política editorial se propone el siguiente mapa del sitio en cuanto a los elementos de organización, localización y acceso que conformarán el "Portal del Conocimiento Jurídico", agrupado de acuerdo a los elementos propuestos: 
Mapa del sitio "Portal del Conocimiento Jurídico" México

\begin{tabular}{|c|c|c|}
\hline Colecciones & Servicios & Divulgación \\
\hline Consulta & Consulta & Noticias \\
\hline Anuarios & Directorios & Boletín PdE \\
\hline 2006 & Documentos AMIJ & Noticias AMIJ \\
\hline 2007 & Acceso a Referencias & Calendario de Eventos \\
\hline 2008 & Biblioteca & Eventos AMIJ \\
\hline 2009 & Archivo & Eventos Apartados \\
\hline 2010 & Legislativo & Premios AMIJ \\
\hline Directorios & Anuarios & Proyectos Premiados \\
\hline impartidores & 2006 & Proyectos Ganadores \\
\hline Consultores & 2007 & Encuestas \\
\hline Programa de TV & 2008 & Libro de Visistas \\
\hline Fichas & 2009 & Redes Sociales \\
\hline Legislativo & 2010 & Twitter \\
\hline Biblioteca & Diarios & Facebook \\
\hline Archivo & Acceso a la Editorial & Blog \\
\hline Cursos & Acceso a Cursos & Foros de Divulgación \\
\hline Acceso a la Justicia y DH & Acceso a la Justicia & Abierto \\
\hline Editorial & SPIGeR en Línea & Cerrado \\
\hline Ensayos & Cursos SNAJ & \\
\hline Documentos AMIJ & Acceso a Noticias & \\
\hline Relatoria & Boletín PdE & \\
\hline Presentaciones & Noticias AMIJ & \\
\hline Archivos PDF y Doc & Acceso a Documentación & \\
\hline Premios AMIJ & Programa de TV & \\
\hline Proyectos Premiados & Docuentos AMIJ & \\
\hline Proyectos Ganadores & Documentos Finales de Proyectos & \\
\hline Documentos Finales de Proyectos & & \\
\hline Diarios & & \\
\hline
\end{tabular}

\section{Integración de información proveniente de instituciones colaboradoras con la AMIJ}

En lo tocante a este proceso es indispensable haber cubierto la parte de "criterios de elegibilidad" de los aspectos editoriales, con el fin de tener por anticipado estos criterios y difundirlos entre los potenciales colaboradores. Pueden ser construidos o perfeccionados recabando las visiones y puntos de vista de las diversas instituciones susceptibles de convertirse en "socias" o colaboradoras de la AMIJ acerca de sus preferencias y necesidades en lo respectivo a literatura acerca del tema de la impartición de justicia y afines. Por medio de un censo pueden recabarse las posibilidades de que esas instituciones eventualmente pudiesen aportar colecciones y servicios al portal. 
En lo tocante a los aspectos editoriales esto servirá para corroborar las secciones que ya han sido establecidas anteriormente en el "mapa del sitio". En lo tocante al censo es necesario tener en mente que su objetivo es medir el interés y capacidad de colaboración de los diversos tribunales, órganos impartidores de Justicia e instituciones afines en la República Mexicana. Para ello es recomendable diseñar, elaborar y aplicar a esas instituciones un "cuestionario" al efecto, el cual permita conocer a la institución -en este caso la AMIJ- acerca de, entre otras cosas, la cantidad, calidad y tipo de información que tiene cada organismo y que es susceptible de ser del interés y de ser compartida con la comunidad usuaria del portal; las características estructurales, documentales y tecnológicas de esa información, el tipo y características del servidor y red en donde se encuentra disponible, todo ello con el fin de poder establecer la importancia, pertinencia y viabilidad de incorporar cada conjunto de información al portal y, en su caso, concertar un proyecto específico de colaboración con esa institución. Se recomienda que el cuestionario cubra todos los aspectos pertinentes a la información a integrar: bibliográficos, informáticos, legislativos y jurisdiccionales.

Hay ventajas que el portal puede ofrecer a esas instituciones de forma tal que les parezca atractivo compartir sus colecciones y acervos. Estas ventajas deben hacerse evidentes hacia esas instituciones al momento de levantar el censo para maximizar el impacto e interés. Entre las principales ventajas distinguimos:

- Aporta a los usuarios un solo punto de acceso inédito para la información de acceso abierto editada en el medio mexicano de la impartición de justicia.

- Proveerá un metabuscador especializado en el tema y dentro del portal.

- Preservará la imagen e identidad de cada sitio y organización asociados.

- Da a conocer la información de cada organización dentro y fuera de su región y del país.

- Potencia la visibilidad de sus contenidos.

- Complementa y enriquece la información de organismos semejantes

- Favorece las sinergias y colaboraciones entre organismos con objetivos afines.

Del resultado del ejercicio de definición de temáticas realizado en los aspectos editoriales, se determinó que existen tres tipos de acervos que son de interés para los usuarios: 
Entre los acervos legislativos que pueden ser integrados al portal están:

- Constitución Política

- Tratados y acuerdos internacionales

- Leyes, Códigos y Reglamentos Federales

- Acuerdos y Decretos Federales

- Constituciones Estatales

- Leyes, Códigos y Reglamentos Estatales

- Acuerdos y Decretos Estatales

- Memorias de sesiones de congresos y cabildos

- Bandos y Edictos Municipales

Entre los acervos bibliográficos, serán de interés del portal:

- Monografías

- Artículos de investigación

- Diccionarios, glosarios y enciclopedias jurídicas

- Ensayos y escritos de opinión jurídicos

- Bibliografías y reseñas

- Noticias y "archivos verticales"

- Ensayos y paráfrasis

- Tesis de grado

- Ponencias y conferencias

- Manuales

- Material didáctico

- Informes y dictámenes jurídicos

Entre los acervos jurisdiccionales, serán de interés del portal:

- Jurisprudencias y tesis jurisprudenciales

- Sentencias y fallos

- Laudos, arbitrios, resoluciones y veredictos

Así como muchos de sus equivalentes a nivel internacional; es decir, fuentes del conocimiento jurídico provenientes de otros países que sean pertinentes a la temática del portal, con objeto de poder hacer estudios y comparaciones internacionales. 


\section{Aspectos tecnológicos}

Se ha establecido que una característica típica de este tipo de portales es su distribución y acceso sobre el servicio WWW montado sobre las redes de comunicación existentes, tales como lnternet, redes metropolitanas, redes Wan y más actualmente servicios GSM -Global System for Mobile Communications- para dispositivos móviles: el hecho de que el portal sea construido sobre una estructura Web hace que frecuentemente se pretenda construirlo simplemente como otro simple sitio Web basado en los paradigmas de construcción de estos sitios. Esto sólo es verdad en parte: en efecto, un portal del conocimiento construido como un sitio Web debe cumplir con una serie de principios y atributos técnicos propios de este tipo de instancias (Web Design Group, 2006), pero sus objetivos, su imagen, su presentación, sus contenidos, etc. deben contemplar y reflejar en lo técnico los otros aspectos adicionales para maximizar su éxito. La omisión de los demás aspectos reduce significativamente las probabilidades de éxito de la publicación. Aclarado esto, y en lo relativo exclusivamente a los aspectos tecnológicos a considerar en el desarrollo de un portal de esta naturaleza, los principales puntos en general son:

1. Dimensionamiento de las capacidades tecnológicas de la institución: tipo y capacidad de servidores, redes, recursos humanos al efecto, etcétera.

2. Dimensionamiento del tamaño de los acervos del portal proyectados a uno, tres y cinco años. Derivado de ello, espacio de almacenamiento requerido en disco.

3. Estimación de la demanda: "hits", descargas, ancho de banda, podcast, etc., proyectados a uno y tres años. Derivado de estos dos puntos, determinación de las características requeridas en el servidor donde se instalará el portal; programas necesarios dentro de él. Determinación del tipo y dimensiones de la red.

4. Establecimiento del entorno institucional de seguridad informática; esto es,

[...] el proceso de establecer y observar un conjunto de estrategias, políticas, técnicas, reglas, guías, prácticas y procedimientos tendientes a prevenir, proteger y resguardar de daño, alteración o sustracción a los recursos informáticos de la organización y que administren el riesgo al garantizar en la mayor medida posible el correcto funcionamiento ininterrumpido de esos recursos.

5. Programas y aplicaciones necesarios para el desarrollo, edición, conversión y publicación de los documentos. 
6. Establecimiento del perfil y nivel de capacitación del personal técnico encargado de recibir, convertir, preparar y "subir" los documentos.

7. Establecimiento de programas y aplicaciones especiales que los lectores requerirán para la consulta de los diversos materiales: "flash", "visualizadores" especializados de imagen, sonido o video, etc., con el fin de poder informar oportunamente a los usuarios de estas necesidades.

8. Establecimiento del o de los sistemas, metodologías y mecanismos de indización o "marcado" de los documentos a publicar para su adecuado registro y recuperación dentro del catálogo y/o base de datos de la institución. Establecimiento de metodología(s): Dublin Core, XML, etcétera.

9. Establecimiento de los estándares técnicos obligatorios mínimos del portal así como de los estándares deseables, y que son derivados de la Política Editorial.

10. Determinación del layout o imagen esquemática del portal y su "mapa del sitio".

11. Costeo y proyección de estos requerimientos tecnológicos, ya que son de los que más incidirá sobre los costos del portal.

12. Adopción de los estándares técnicos de construcción mínimos y obligatorios del portal Web, los cuales pueden variar dependiendo del resultado del estudio realizado dentro de los aspectos editoriales acerca de los requisitos y condiciones establecidos por el medio de la red respecto a estos sitios (Zeldman, 2006).

Llevando lo anterior a la práctica, en el aspecto tecnológico se establecieron los principales elementos de este tipo con los que debe contar el portal del conocimiento de la AMIJ más allá de su contexto editorial. Además, se establecieron las capacidades de almacenamiento y acceso a los que podría verse sometido el portal en los primeros dos años; se determinó que las capacidades actuales de los servidores de la AMIJ pueden contender perfectamente con esta carga adicional durante este periodo. A continuación se estableció que el portal del conocimiento debe contar con su propio espacio autónomo dentro de los servidores de la AMIJ, al margen de otras aplicaciones y publicaciones del mismo. Por ello se tramitaron ante los organismos competentes de Internet los nombres pertinentes para el portal con objeto de hacer el registro correspondiente del URL cubriendo varias posibilidades de acceso a la misma. Se establecieron y presentaron los fundamentos y recomendaciones técnicas respecto a un plan de seguridad informática inherente a la AMIJ y en especial a su portal. Se calculó y estableció que el almacenamiento requerido para el 
portal Web en sus primeros dos años es de aproximadamente cien gigabytes de espacio para programas, aplicaciones y área de maniobra, así como doscientos gigabytes adicionales para los materiales a publicar en sus diversas versiones además de sus índices y metadatos.

Por lo general el diseño de un sitio Web contempla las siguientes funciones o personas:

1) Gestor de Contenidos; en este caso la persona designada como "editor" del sitio.

2) Supervisor de Contenidos; en este caso el Secretario Ejecutivo de la AMIJ.

3) Desarrollador Web. Persona con perfil técnico en informática encargada del desarrollo, programación, estructuración y actualización de las aplicaciones para que el sitio Web funcione (interno o externo).

4) Diseñador Web. Persona con perfil en diseño gráfico o artes visuales encargada de la imagen del sitio Web (interno o externo).

Para que el personal técnico de la AMIJ o terceros puedan construir el portal Web del conocimiento jurídico se establecieron previamente las siguientes especificaciones; están destinadas mayormente al desarrollador Web y en algunos casos al gestor y supervisor de contenidos para ayudarlo a estructurar la página; para el diseñador Web sólo contiene especificaciones generales.

Estándares técnicos obligatorios minimos asi como estándares deseables del Portal del Conocimiento Jurídico de la AMIJ derivados de la Politica Editorial.

\section{Especificaciones generales}

El portal debe contar con su propio URL ${ }^{2}$ del tipo “.org" independiente del utilizado por la institución; es decir, no debe ser un simple subconjunto -"slash" o "dos puntos"- del sitio principal de la institución. Este URL debe aparecer explícitamente en todas las subpáginas Web del portal, incluyendo las de los contenidos, para oportuna identificación, citación y referencia.

La construcción de la página principal y subpáginas del portal Web debe cumplir con las especificaciones y recomendaciones para HTML emitidas por

2 URL o "Universal Resource Locator": “Localizador Uniforme de Recursos”; se refiere a la dirección única que identifica a una página dentro de la WWW, como por ejemplo http://www. unam.mx 
$\mathrm{W}_{3} \mathrm{C}^{3}$ en cuanto a usabilidad, tipos de fuentes, colores, distribución física, navegación, etcétera (W3C, 2011). Sobre todo debe funcionar compatiblemente con la mayoría de los navegadores existentes (Explorer, Firefox, Opera, Safari, Chrome, etc.) hasta una versión atrás de la actual. Por ningún motivo debe quedar atada a un navegador en específico ni ostentar ninguna leyenda de "esta página se ve mejor con....".

Todas las páginas del portal deben poder ser conmutadas en sus textos propios (no en sus contenidos) al idioma inglés con un botón claramente visible en la página principal.

La página y todas las subpáginas del portal deben tener un hipervínculo visible al sitio Web principal de la AMIJ. Todas las subpáginas deben tener un botón muy claro de "regreso a página anterior" y otro de "inicio" (home). Debe evitarse en lo posible la necesidad de utilizar para ello la barra de herramientas del navegador.

Las páginas deben respetar el límite establecido de 1024 pixeles horizontales. No debe hacerse uso de la barra de desplazamiento horizontal para poder leer las páginas. El límite vertical de cada página no debe ser mayor al equivalente a dos páginas para evitar excesivo uso de la barra de desplazamiento vertical (scroll down). En caso de ser mayor, debe romperse la página. No obstante, la estructura del sitio debe evitar en lo posible rutas (paths) que profundicen muchos niveles de subpáginas abajo de la principal. Entre tres y cinco niveles es ideal.

El sitio Web debe contar con una distribución clara y consistente que permita al usuario identificar rápidamente las áreas o zonas que la componen (navegación, menús, despliegue de información, etcétera).

Con la finalidad de que el usuario reciba la imagen diseñada originalmente deben utilizarse exclusivamente fuentes tipográficas estandarizadas: Arial, Verdana, Times New Roman, Georgia, etc.

$\mathrm{Si}$ se requieren aplicaciones adicionales (plug-in) para visualizar la página Web o alguno de sus componentes, debe notificarse oportunamente al usuario y agregarse el vínculo al sitio Web donde pueda descargarse esa aplicación (por ejemplo Acrobat Reader), así como instructivos claros para proceder a su instalación.

Identificar clara y explícitamente el destino de cada hipervínculo además del URL.

En las partes del portal donde el usuario puede descargar artículos PDF, aplicaciones, imágenes, etc., debe cuidarse que el peso de cada uno de los

3 W3C o "World Wide Web Consortium", es un consorcio internacional que produce recomendaciones y estándares para la WWW, en especial en lo tocante a URL's, el protocolo http y el lenguaje HTML. 
archivos no sea excesivo a anchos de banda modestos; en caso de ser archivos de tamaño considerable, estos deben romperse previamente en trozos manejables.

Llenar adecuada y prolijamente los "metanames" y "metatags" de las páginas HTML para facilitar a los buscadores la indización máxima y por tanto mejor recuperación de las páginas del sitio.

En lo posible, todos los materiales deben ser publicados en formatos estándar: HTML, PDF, txt u "hojeable" (flippable). Los materiales en otras formas deben ser aprobados previamente por el editor y siempre tratando de apegarse a formatos estándares y ampliamente difundidos.

No utilizar tablas anidadas, medidas en pixeles o unidades absolutas en el código ni en las hojas de estilo.

En el caso de artículos, ensayos, y otros materiales que contengan páginas de texto, se recomiendan las siguientes especificaciones:

1. El URL del portal debe aparecer explícitamente en todas las páginas físicas del documento, para oportuna identificación, citación y referencia.

2. Cada artículo o material publicado debe contar al inicio del mismo con un "membrete bibliográfico" apropiado; esto es, consignar siempre de entrada, además del nombre del sitio Web, el o los nombres de los autores (de una forma normalizada), su institución y dependencia de adscripción, su correo electrónico profesional, la fecha de publicación del documento, así como el título del artículo o material y sus resúmenes. El nombre de los autores, fecha de publicación y título del artículo deben repetirse de manera discreta en un pie de página o encabezado en todas y cada una de las páginas de los artículos.

3. Cada artículo o material publicado debe ser transformado de su forma original a una forma "editable" normalizada aprobada previamente por el responsable del sitio con objeto de mantener una imagen editorial homogénea.

4. La totalidad de los trabajos publicados en los números anteriores del portal debe quedar accesible de forma acumulada, con algún mecanismo de acceso y/o búsqueda de esos materiales.

\section{Especificaciones de la página principal}

La página Web principal del portal debe contar con las siguientes "zonas" o secciones: 
1. Zona de encabezado. La página Web del portal debe contener los siguientes elementos:

1) Escudo-logo oficial de la AMIJ

2) Nombre completo de la AMIJ + "México"

3) Nombre completo oficial del Portal del Conocimiento Jurídico

4) Nombre mnemónico corto del portal si, existiese.

2. Zona del "mapa del sitio".

3. Zona de "derechos de autor" o "Copyright" con hipervínculo a un recuadro que declare que todos los trabajos publicados -salvo que se especifique explícitamente otra cosa- tienen una licencia de "Commons" bajo el esquema cc by-nc-sa. Attribution Non-Comercial Share Alike 2.5, Unported, o "Por atribución, No-Comercial, Compartir bajo la misma licencia - versión 2.5”. Debe estar consignado en este recuadro el texto legal completo de la licencia modelo, incluyendo ícono. Las especificaciones, muestras y paletas de colores se encuentran en: http://creativecommons.org/about/downloads

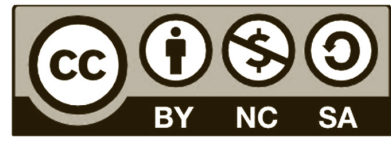

4. Recuadro resumen de la "página descriptiva (portada)" en la página principal del sitio del portal, consignando: el nombre oficial del portal, el nombre de la AMIJ como editor, objetivo del portal y sus coberturas temáticas.

Este recuadro debe tener un hipervínculo a una "Página Descriptiva (portada)" completa, en donde se consignen claramente:

- El nombre oficial del sitio Web, las instituciones asociadas o participantes que aportan colecciones claramente detalladas, correo electrónico oficial del sitio Web.

- El nombre completo de la AMIJ editor, más la leyenda "México".

- Su dirección postal completa.

- El nombre, cargo y correo electrónico del responsable editor del portal.

- Correo electrónico oficial del portal.

- Su descripción breve, objetivo, alcance y cobertura temática.

- La portada debe estar traducida al inglés para ser conmutada con el botón de idioma.

5. Zona, línea o recuadro de "si deseas someter algún material al sitio web” con hipervínculo visible al editor. 
6. Una "zona de colofón" en la parte inferior de la página con los siguientes elementos:

- La leyenda: 'Ciertos Derechos Reservados Sobre el Sitio Web. AMIJ -Asociación Mexicana de Impartidores de Justicia, A.C.-' en inglés y español.

- Botón de "créditos" de la página Web, la cual a su vez contiene dentro de ella una zona de "créditos históricos" para poder actualizar a los responsables a lo largo del tiempo.

- Botón de "contacto" especificando que se trata de contacto para aclaraciones y dudas sobre el sitio Web. Debe consignarse correo electrónico y teléfono del responsable del contacto del sitio.

- Fecha de última actualización del sitio Web.

- Zona del "Directorio" del sitio Web.

- Zona de "Visitantes" y estadísticas.

\section{Especificaciones generales de diseño gráfico}

El sitio Web institucional del Portal del Conocimiento Jurídico de la AMIJ debe contar con una identidad gráfica que transmita el sentido de pertenencia institucional al sitio Web principal de la AMIJ y a su comunidad.

La imagen gráfica del sitio del portal debe contar con una resolución ideal de 1024 x 768 pixeles con un mínimo de 800 x 600 .

La imagen gráfica seleccionada para el sitio no debe afectar su funcionamiento, no debe ser de peso excesivo y debe conservar tiempos promedio de carga y recarga razonables.

El contenido gráfico no debe obstaculizar el posicionamiento del sitio Web; antes bien debe facilitar su rastreo e incorporación a bases de datos y buscadores.

La presentación de contenidos en cada página debe respetar la estructura usual jerárquica de izquierda a derecha, arriba a abajo.

El contraste de la letra y su relación color-tamaño debe permitir leer todos los textos, inclusive de los letreros más pequeños, aun en pantallas pequeñas y de pobre contraste tipo netbook, o $\mathrm{Pad}$ y teniendo en mente a personas con discapacidades visuales. Los colores de fondo siempre deben ser claros y las letras en colores oscuros para maximizar la legibilidad y facilitar la impresión.

\section{Especificaciones futuras deseables}

En un periodo corto, es deseable que el sitio Web incluya el mayor número posible de los siguientes elementos de valor añadido: 
- Buscador de materiales dentro del portal (autores, títulos, palabras clave, etcétera).

- Servicio de "Alerta" de nuevos materiales recién aparecidos en las diversas secciones.

- Servicio de "Diseminación Selectiva de Información" donde se construya una base de datos depersonas interesadas en ciertos temas y se envíen materiales nuevos a los correos de esas personas.

- Servicio de enlaces sindicados de fuentes Web codificadas en XML (RSS).

- Foros de discusión moderados.

- Materiales descargables por podcast y/o webcast.

- Desarrollo de recursos informáticos y normatividad adicionales para fomentar la interoperabilidad y ampliar la cobertura.

Debido a la existencia de una gran variedad de dispositivos de acceso móvil que cuentan con diferentes características y limitantes, es recomendable tomar en cuenta las siguientes pautas para conservar la consistencia y uniformidad del contenido al acceder a una URI:

- Verificar que el contenido es adecuado para el contexto de dispositivos móviles.

- Presentar el contenido principal de la página al inicio.

- Restringir el uso de páginas que se actualicen automáticamente; si se requiere hacer uso de ellas, informar al usuario y proporcionar los medios para detener la actualización.

- Restringir el número de vínculos a recursos externos.

- Restringir el redireccionamiento automático.

- Utilizar un juego de caracteres que sea soportado por una gran variedad de dispositivos portátiles.

- Realizar pruebas tanto en emuladores como en dispositivos reales.

- Mantener mecanismos de uso y navegación consistentes y cómodos de utilizar desde los diferentes mecanismos utilizados por dispositivos móviles.

- Proporcionar un menú de navegación reducido al inicio de la página.

- Asignar teclas de acceso rápido a los enlaces del menú de navegación y las funcionalidades usadas frecuentemente.

- Reducir la captura de texto, proporcionando valores por defecto preseleccionados.

- Mantener el número de teclas a pulsar -máximo cinco por página-.

- Evitar la saturación visual del sitio al mantener un diseño simple y ligero que tome en cuenta las limitaciones de recursos y características de los diferentes tipos de dispositivos. 
- Utilizar código conciso y eficiente que optimice el uso de los recursos disponibles.

- Mantener el tamaño de la página en porciones acordes a los mecanismos de despliegue de los dispositivos y limitar el uso de las barras de desplazamiento sólo a una dirección.

- La combinación de colores en primer plano y de fondo deben contrastar entre sí.

- Indicar el tamaño deseado de las imágenes en el código.

- El peso total de la página debe tomar en cuenta las limitaciones de memoria de los dispositivos portátiles.

- Evitar el uso de imágenes de fondo, mapas de imágenes, imágenes de alta resolución, imágenes para crear espacios en blanco, ventanas emergentes, marcos -frames-, tablas, cookies, así como cualquier elemento no soportado por la generalidad de dispositivos móviles (Mobile..., 2006).

\section{Aspectos bibliotecológicos}

El desarrollo de estos aspectos tiene que ver con la necesidad de asegurar la calidad y homogeneidad de los contenidos desde un punto de vista bibliotecológico y/o de la ciencia archivística, estandarizando en lo posible la estructura de los registros al tiempo que se facilita su búsqueda, recuperación e inserción dentro de otros mecanismos localizadores dentro de la Web más allá del ámbito cercano del portal. Dentro de los "aspectos editoriales" ya hemos mencionado una serie de elementos de calidad que también tienen que ver con los aspectos bibliotecológicos: desarrollo de una portada o membrete estandarizado, etc. Es pertinente en este punto agregar además el desarrollo de elementos bibliotecológicos y archivísticos.

Dado que muchos de los acervos y contenidos provendrán de instituciones externas a la AMIJ, la naturaleza, tipo, cantidad y variedad de los registros de los materiales será muy variado. No obstante, y para mantener en lo posible la calidad del conjunto documental, la organización vigilará que no ingresen al acervo materiales que no tengan ningún tipo de registro y metadatos o que estos sean de ínfima calidad. En su caso, establecerá proyectos de asesoría a instituciones externas para dotar de registro y metadatos a esos acervos. Todos los documentos producidos por la AMIJ deben contar sin excepción con estos elementos.

De la misma forma, y dado que en el portal pueden concurrir acervos documentales provenientes de diversas instituciones, es necesario desarrollar un sistema de registro y búsqueda normalizado de todos los materiales contenidos 
para poder localizarlos de forma eficaz dentro del ámbito del portal. No es necesario que todos los contenidos dentro del portal tengan la misma metodología de indización de origen, pero sí que exista un mecanismo dentro del portal que permita normalizar después de su ingreso la forma de registrar, buscar y recuperar los contenidos dentro del portal. Esto es de vital importancia para el éxito del sitio, ya que de otra forma la desnormalización puede crear niveles de confusión, pérdida o duplicación de la información recuperada más allá de lo admisible.

Para establecer lo anterior puede usarse una metodología que contemple algún o algunos de los elementos enumerados a continuación:

1) El portal debe cumplir de inicio con los estándares de calidad y presentación estipulados ya en el apartado de aspectos editoriales, resultado del estudio de los requisitos y condiciones establecidos por los principales repositorios bibliográficos así como de las organizaciones evaluadoras, calificadoras e indizadoras de las publicaciones digitales: periodicidad, actualización frecuente, indización, contenido y colofón, etcétera.

2) Como consecuencia de la política bibliotecológica, todos y cada uno de los materiales o artículos publicados debe tener su conjunto de metaetiquetas en alguna especificación preestablecida por la institución editora. Entre más rico o sofisticado sea el conjunto de metaetiquetas, más facilitará su hallazgo después por los buscadores de la Web, condición que adquiere suma importancia ya que el portal se distribuye por esta vía. En la práctica se observa el uso de los estándares METS -The Metadata Encoding and Transmission Specification-y MODS -The Metadata Object Description Scheme- como sistemas de manejo de metadatos construidos sobre una tradición MARC (Dappert, 2008). El conjunto mínimo recomendado de metadatos es el de Dublin Core (Apps, 2000) ${ }^{4}$. Cada vez más se observa el uso de estos estándares dentro de los portales bajo codificación XML. Independientemente del sistema a ser usado, el punto vital aquí es que las metaetiquetas asignadas a cada material se vean reflejadas en los "headers" de la versión HTML del documento para que puedan ser recuperadas con más precisión y facilidad por los buscadores de la red y así maximizar la accesibilidad y distribución de esos materiales dentro de la Web. Si este conjunto de metaetiquetas no viene de origen debe ser agregado en el ámbito del portal.

4 Ministerio de Ciencia e Innovación de España (2010). Consejo Superior de Investigaciones Científicas. Formatos estándar de metadatos para revistas científicas. Disponible en: http:// digital.csic.es/documentos/Formatos_plantillas_DC_articulos.pdf 
3) Todos los artículos propiamente dichos ya formados y editados por la AMIJ deben estar normalizados en su estructura de acuerdo a un estándar preestablecido por ella, como por ejemplo la norma ISO 215:1986 "Documentación: Presentación de Contribuciones a revistas y otras publicaciones periódicas”.

4) Cuando sea posible, los materiales publicados debe tener un abstract o resumen y un conjunto de palabras clave tanto en inglés como en español.

5) Las citas y/o referencias bibliográficas deben ser incluidas en los artículos bajo una estricta estandarización que permita en un futuro agruparlas e hipervincularlas; se recomienda el uso del estándar ISO 690-1:1987 -documentos impresos- e ISO 690-2:1997 -documentos electrónicos-, o uno semejante.

6) Para facilitar su descarga, lectura, citación y reuso, cada artículo debe estar accesible al lector en más de una versión; se recomienda usar formatos HTML, PDF descargable y versión electrónica de "hojas plegables" o "flip page" : en el caso de que así se haya establecido previamente, deberán existir además las versiones "ligeras" de los artículos para dispositivos móviles: netbooks, tabletas, celulares, etcétera.

7) Cada artículo o material publicado debe contar siempre con un "membrete bibliográfico" apropiado y estandarizado; esto es, consignar siempre en su primera página y de una forma totalmente normalizada, todos los elementos bibliográficos del mismo: además del nombre del portal, el o los nombres de los autores, su institución y dependencia de adscripción, su correo electrónico profesional, las fechas de sometimiento a arbitraje, de aceptación y de publicación del documento, así como el título del artículo o material y en su caso, sus resúmenes bilingües. Además del membrete de la página principal, en todas y cada una de las páginas adicionales de los artículos deben repetirse de manera discreta en un pie de página o encabezado el nombre del portal, su URL, el nombre de los autores, fecha de publicación y título del artículo para oportuna identificación, citación y referencia. Este elemento refuerza además los aspectos legales consignando claramente en cada página de cada artículo la propiedad intelectual de la institución editora.

5 Se define como "hoja plegable" o "flip page" a las aplicaciones computacionales que simulan que una imagen digital de una página de un libro, revista etc. sea "hojeada" o pasada de un lado a otro como si fuera la página de un libro en papel. Véase http://www.flashpageflip.com 
8) Es recomendable que la institución editora estudie la conveniencia de adoptar el número DOI "Identificador Digital de un Objeto", para cada artículo; si decide adoptarlo, este debe ser consignado en el membrete y en cada página adicional del artículo.

\section{Aspectos legales}

En este aspecto se determinan y establecen los mecanismos para asegurar la propiedad patrimonial de los documentos publicados por el portal: registros, cartas de cesión, etc.; unicidad o multiplicidad de usos y versiones, exclusividad, compromisos de inedición previa, de uso de acervos de terceros, etc., así como se establecen las condiciones de reproductibilidad de los documentos publicados en el portal: licencias, citas, modificaciones, atribuciones, colaboraciones, etc. (La declaración de "commons" propia del portal).

En particular, en este aspecto se trabajaron los siguientes elementos:

1) Se recomendó registrar la Reserva de Derechos para el Uso Exclusivo de la representación gráfica y los distintos logos, lemas, etc. del portal Web del conocimiento de la AMIJ ante el Instituto Mexicano de la Propiedad Industrial (IMPI), así como la Reserva de Derechos para el Uso Exclusivo tanto del Sitio Web como de los nombres de dominio ante NIC México; ${ }^{7}$ lo anterior con objeto de proteger todos los registros de ley de nombres y dominios. La pertinencia de registrar los elementos gráficos mencionados es garantizar que la AMIJ tenga el uso exclusivo de los mismos y reserve todos los derechos para su publicación, distribución y comercialización.

2) Determinación y establecimiento de los mecanismos para -en su caso- asegurar la propiedad intelectual de los materiales publicados en el portal o, en su defecto, para los provenientes de otras instituciones el derecho de uso de los mismos. Se diseñaron cartas de declaración

6 El número DOI -Digital Object Identifier-es un sistema parecido a los identificadores ISBN e ISSN, pero creado para cada documento en particular que se publica. Para utilizarlo, se obtiene una membresía por parte de la International DOI Foundation; se envía y se registra cada artículo o material científico en el sitio al efecto y se recibe un número DOI para anexar a este material. A diferencia del sistema URL, el sistema DOI no cambia con el paso del tiempo, aunque el artículo sea reubicado en una dirección Web distinta puesto que lleva la información incorporada en forma de metadatos. Puede considerarse un URL permanente. http://www. doi.org

7 NIC. Un operador de registro denominado "Network Information Center" (en español: Centro de Información de Redes); es parte del DNS (Domain Name System o Sistema de Nombres de Dominios) de la Internet que guarda la base de datos de los nombres de todos los dominios y convierte los nombres de dominio a direcciones IP. Hay uno en cada país además de los internacionales. 
de dominio público, cesión de derechos, unicidad o multiplicidad de usos y versiones, exclusividad, compromisos de documento inédito previamente, etcétera.

3) Establecimiento de las condiciones de reproductibilidad de los documentos publicados en el portal: licencias, citas, modificaciones, atribuciones, colaboraciones, etc., para ambientes académico, jurídico, etc. Se estableció lo que debe aparecer en el texto del sitio Web como la declaración de "commons" propia del portal. En este sentido y en resumen, se estableció lo siguiente:

- Los acervos o trabajos pueden presentarse por un autor personal, un grupo de autores o a nombre de una organización o institución con un nombre de responsable de la publicación, donde se especifiquen las condiciones legales de propiedad patrimonial, uso y reproductibilidad.

- Los responsables y/o autores que sometan materiales para publicación en el portal deberán cumplir con alguna de las siguientes disposiciones:

a) Ser los titulares de los derechos patrimoniales de propiedad intelectual; en el caso de autores, estos deben ser los autores primigenios para obras originales.

b) Contar con autorización por escrito del titular de los derechos en caso de ser traducciones, adaptaciones, etc., o

c) Mostrar evidencia de que la publicación de la que proviene la obra ha cedido sus derechos a dominio público o a otro mecanismo autorizado de reproducción con "ciertos derechos reservados" (Creative Commons, GNU General Public License o GPL, Wikimedia Commons, etc.) y el trabajo sometido cumple con estos requisitos.

- Los derechos patrimoniales de los materiales aceptados para publicación serán cedidos por escrito a la AMIJ para su publicación en el portal. Los derechos morales de los autores serán invariablemente reconocidos y consignados en todas las publicaciones de la AMIJ. Los derechos de publicación no quedan en exclusividad para la AMIJ, reteniendo los autores su derecho a publicar sus materiales posteriormente en otras ediciones.

- Salvo que previamente se especifique lo contrario, todos los materiales que se publiquen en el Portal del Conocimiento Jurídico de la AMIJ serán publicados bajo una licencia de "commons" bajo el esquema cc by-nc-sa. Attribution Non-Comercial Share Alike 2.5 Unported, o (Reconocimiento, No-Comercial, Compartir bajo 
la misma licencia - versión 2.5). En caso de que el titular o autor deseara un esquema distinto de "commons" deberá especificarlo al momento de someter su trabajo explicando las razones para ello.

- El envío de cualquier material u obra al portal supone el compromiso del autor de no someterlo entretanto a la consideración de otros editores.

- El portal se compromete a publicar todos los materiales aprobados y a conservarlos accesibles en el sitio durante todo el tiempo establecido en su política editorial.

El logotipo a adicionar en el sitio Web del portal es el siguiente:

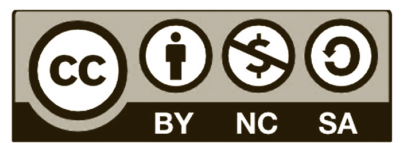

El detalle completo de la licencia de "creative commons" seleccionada para el portal Web del conocimiento jurídico: "reconocimiento 2.5, unported, (cc by-nc-sa 2.5)" debe ser apuntado desde el sitio Web del portal hacia: http://creativecommons.org/licenses/by-nc-sa/2.5/mx/. Ya que los autores y responsables al llenar su carta de cesión de derechos manifiestan haberlo leído, conocido y aceptado.

Dado que se trata de un portal que distribuye sus contenidos de forma digital y remota, estos aspectos son de suma importancia para la institución editora, ya que le permiten asegurar la propiedad intelectual de los materiales que edita pero buscando al mismo tiempo maximizar su alcance y distribución. Estos dos elementos son de suma importancia y rigen prácticamente todo el desarrollo de los aspectos legales. Por un lado el portal debe asegurarse que posee efectiva y cabalmente los derechos patrimoniales -esto es, de explotación- de cada contenido que distribuye con objeto de evitar futuras reclamaciones y disputas debidas a lagunas o acuerdos tácitos. Por otro lado, es lógico desear la máxima penetración del portal, y por ello debe diseñarse un fácil y amplio acceso, uso y distribución de sus materiales dentro de la comunidad a la cual se dirige la publicación. Para esto, la institución debe comenzar con la determinación exacta de las características legales con las que adquiere las colaboraciones y guardar documentación escrita de lo anterior, así como establecer y explicitar muy claramente las condiciones de reproducibilidad de los documentos publicados en el portal; esto es, cuál es el tipo de licencia que está otorgando a los lectores de la misma con respecto 
a los contenidos; cuáles son las atribuciones y límites otorgados al lector y las condiciones en las que él puede acceder, descargar, usar, o modificar esos materiales, tanto para ambientes comerciales como académicos, ya que es naturalmente deseable que el portal y los materiales publicados sean citados adecuadamente

Para establecer lo anterior puede usarse una metodología que contemple los elementos enumerados a continuación:

1) Con objeto de asegurar la propiedad y unicidad del nombre del portal es necesario crear una "Reserva de Derechos de Uso Exclusivo". El artículo 173 de la Ley Federal del Derecho de Autor señala que esta consiste en la facultad de usar y explotar en forma exclusiva títulos, nombres, denominaciones, características físicas y psicológicas distintivas, o características de operación originales aplicadas de acuerdo con su naturaleza. Esto debe hacerse con el nombre oficial y estándar del portal -nombre largo- y en su caso el nombre mnemónico o corto ante el Instituto Nacional del Derecho de Autor-INDAUTOR- y en su caso ante el IMPI -Instituto Mexicano de la Propiedad Industrial-. Debe tramitarse además el nombre de dominio del sitio Web exclusivo del portal ante NIC México o algún representante. En su caso, si se involucran en el portal logos o marcas deberá hacerse el registro correspondiente ante el IMPI, todo lo anterior con objeto de tener asegurados todos los registros de ley de nombres y dominios.

2) Determinación y establecimiento de los mecanismos que aseguren a la institución editora la propiedad patrimonial permanente de los documentos publicados por el portal: cartas de cesión de derechos patrimoniales por parte de los autores, estableciendo unicidad o multiplicidad de uso y versiones, exclusividad, compromisos de documento inédito previamente, originalidad de la publicación, titularidad de los derechos como autor o autores primigenios, etc.; tales cartas deben elaborarse en todos los idiomas en los que se acepten materiales documentales por parte del portal y obtenerse sin excepción por parte de todos los titulares o autores previo a la publicación. Esto asegura la propiedad patrimonial de los materiales del portal por parte de la institución al tiempo que la deslinda de futuras reclamaciones autorales.

3) Determinación y establecimiento de las condiciones de reproducibilidad de los documentos publicados en el portal por parte de los lectores: licencias, citas, modificaciones, atribuciones, colaboraciones, obras derivadas, etc., para ambientes académicos y/o comerciales. En su caso, determinación de los costos de estos licenciamientos. En el 
caso de portales que deciden no trabajar bajo el esquema de "todos los derechos reservados" lo más común es operar y licenciar bajo el esquema de "ciertos derechos reservados": esquemas de licenciamiento "Open Access" tipo GNU -General Public License o GPL-, o el más utilizado de todos estos en la actualidad, la estructura conocida bajo el nombre de "commons". Se deben analizar y seleccionar los atributos deseados del portal bajo este régimen, registrarlos en su "Política Editorial" y hacerlos claramente explícitos a sus lectores y potenciales autores; esto se realiza consignando en el texto de la página Web del portal la declaración de "commons" propia del mismo. En términos generales, el conjunto de atributos más comúnmente seleccionados para este tipo de portales es el denominado "cc by-nc-sa". Attribution Non-Comercial Share Alike 2.5 Unported, o -Reconocimiento, NoComercial, Compartir bajo la misma licencia, versión 2.5-. El detalle completo de este tipo de licencia de "Creative Commons" puede verse en: http://creativecommons.org/licenses/by-nc-sa/2.5/mx/legalcode

\section{Aspectos administrativos y financieros}

El aspecto administrativo tiene que ver con los elementos que la institución editora debe planear y ejecutar para la difusión y penetración del portal antes y después de ser lanzado con objeto de lograr su posicionamiento en el medio. Tiene que ver también con el acopio y análisis de información que permita a la institución editora retroalimentar los resultados y tendencias de usuarios, autores, etc., hacia acciones que corrijan posibles debilidades y potencien las fortalezas del portal. El aspecto financiero requiere de un plan cuidadoso a corto y mediano plazo. Entre los principales problemas que enfrentan los portales Web se encuentra la alta "mortalidad prematura". Estos problemas provienen principalmente de dos causas: la falta de contenidos documentales de buen nivel para los portales, lo cual tiene que ver con su posicionamiento, aceptación y calidad, y en segundo lugar la falta de financiamiento de la institución editora.

Para establecer lo anterior puede usarse una metodología que contemple los elementos enumerados a continuación:

1) Estrategia de penetración y "mercadeo" del portal. Por lo general esto se basa en dos líneas de acción: en primera instancia se busca lo más rápidamente posible la acreditación del portal ante la comunidad lectora; esto se puede lograr desde el inicio produciendo contenidos de alta calidad e interés para esa comunidad. En la medida que 
la calidad y penetración del portal crece, más instituciones y autores de importancia se van obteniendo, y la reputación y visibilidad se ven así incrementadas creando así un círculo virtuoso. Por supuesto, esa alta calidad debe ser mantenida a lo largo del tiempo, situación que no siempre es fácil de lograr; si la calidad decrece y se pierde credibilidad en el portal, el círculo se irá convirtiendo en vicioso. En segunda instancia -y a mediano plazo- se busca la inclusión dentro del mayor número posible de los repertorios bibliográficos y bases de datos del medio.

En el caso de que el portal funcione bajo el concepto de "acceso abierto" es conveniente -una vez teniendo el sitio establecido y en operación- consignar el URL y sus características dentro de los sitios mundiales que registran e indizan a los portales de este tipo.

2) Establecer las bases de los mecanismos que se usarán para detectar las características y perfil de los lectores: encuestas en el sitio Web, cuentas de acceso, descargas, regresos, dominios desde los que se accede, etc. Es importante empezar a establecer claramente desde el principio del portal los perfiles de los usuarios de la manera más detallada posible y establecer los contadores pertinentes para ir recabando la información. Como es ya sabido, la simple cuenta de accesos -"hits"-al sitio no basta.

3) Establecer el perfil del encargado de diseñar, aplicar e interpretar estos sondeos con fines de retroalimentación al portal. El Consejo Editorial debe establecer y supervisar planes y medidas de retroalimentación con los resultados así obtenidos para incrementar la calidad del portal y así corregir eventuales fallas y omisiones y potenciar las fortalezas y aciertos.

4) Establecer un plan de viabilidad y alternativas financieras del portal. En su caso, desarrollo del plan comercial del portal de acuerdo al perfil económico enunciado en el perfil editorial. Establecimiento de materiales y/o versiones susceptibles de cobrarse así como sus posibles valores, destinatarios, descuentos, etc. Establecimiento de la posibilidad de que exista publicidad pagada, y en este caso, tipo, alcance y condiciones de la misma. En el caso de la AMIJ se estableció que la publicación será financiada íntegramente por la propia institución.

5) Establecer el plan de mantenimiento y renovación de la infraestructura tecnológica relativa al portal. 
Como ha podido observarse, el diseño e implementación de un portal del tipo "observatorio virtual" o "portal del conocimiento" no puede hacerse simplemente ajustándose a los principios que rigen la creación de un sitio Web tradicional de papel, ni bajo una óptica estrictamente computacional como si se tratase del desarrollo de un sitio Web más; estas visiones parciales afectan sensiblemente y de forma negativa las características del portal, reduciendo sus probabilidades de éxito y prevalencia. Como se ha establecido, la construcción profesional de una portal Web de alguno de estos tipos conlleva un enfoque más holístico, una visión de variados aspectos transdisciplinarios que influyen en su desarrollo adecuado y consecuente éxito. Hemos agrupado y desarrollado estos factores en: aspectos editoriales, tecnológicos, bibliotecológicos, administrativo-financieros y finalmente aspectos legales. El correcto análisis, ponderación, inclusión, balance e implementación de todos estos aspectos al momento de conceptualizar, diseñar y construir un Observatorio Virtual o un Portal del Conocimiento en una cierta institución maximizan su posible aceptación y éxito por parte de la comunidad correspondiente así como de las instituciones patrocinadoras.

Gracias a los movimientos de "Open Access", "Commons", "Repositorios Institucionales", etc., un número cada vez mayor de instituciones en todo el mundo ha comenzado nuevamente a contemplar la salida de sus resultados y productos a través de la construcción de Portales del Conocimiento (Melero, 2005). Muchas de las instituciones mexicanas dedicadas a la impartición de justicia están también en capacidad de aprovechar su infraestructura tecnológica y sus recursos humanos de alto nivel y especialidad dotándose de una herramienta, un Portal del Conocimiento Jurídico, que impulse su quehacer para el avance y perfeccionamiento de este campo en México, dando sinergia al proceso de generación de conocimientos y desarrollos tecnológicos originales y de punta ampliando y fortaleciendo su posicionamiento en el ámbito judicial. Igualmente, un portal así articula los procesos de generación y transferencia de conocimiento e innovaciones con las necesidades de sus usuarios y socios institucionales permitiéndoles insertarse en su contexto en óptimas condiciones para intercambiar información, conocimiento y habilidades con otras organizaciones, tanto de gobierno como de la sociedad civil que requieren de sus resultados y conocimientos para la solución de problemas.

Partiendo de la voluntad política para desarrollar este tipo de proyectos y yendo más allá de los problemas inherentes al desarrollo de este tipo de publicaciones Web - tecnológicos, financieros, etc. - es necesario emprenderlos de una manera profesional, integral y planeada de tal forma que las probabilidades de 
éxito se maximicen; no hacerlo así pone en riesgo la viabilidad del proyecto a mediano y largo plazo. Muchas de los portales desaparecen al cabo de poco tiempo debido precisamente a esta falta de planeación e integración de los aspectos críticos que inciden en la producción de un portal de esta naturaleza: la carencia de un plan integral de desarrollo, de personal editorial y técnico especializado profesionalmente en el tema o la falta financiamiento las lleva con frecuencia a falta de regularidad, pobre producción y falta de calidad en contenidos y servicios teniendo como consecuencia baja aceptación de la comunidad objetivo y de las instituciones patrocinadoras, desembocando en un proyecto fallido.

Finalmente, una vez que se tenga el proyecto detallado para cada uno de los aspectos deberá dárseles forma, cuerpo y articulación para volverlos un todo coherente. Como todo buen proyecto, deberá contar elementos adicionales tales como tiempos de ejecución, flujos de ejercicio del financimiento, definición de responsables y acciones de inicio. Deberán ser también especificados los mecanismos detallados de seguimiento, evaluación, rendición de cuentas y retroalimentación del proyecto. Deberán ser tomadas las medidas alternativas en caso de que alguno de los resultados no esté funcionando de acuerdo a lo planeado. El proyecto institucional podrá y deberá ser construido permanente y colectivamente por los miembros de la organización, a partir de las interpretaciones evolutivas que existan del mismo. Esto contribuirá de mucho mejor forma para un futuro a mediano y largo plazo pensando en que puede ser reconstruido, complementado y enriquecido por la acción de los distintas personas, organizaciones y sectores que puedan verse involucrados en el esfuerzo. Tomará un tiempo desarrollarlo; pero de seguro que uno de sus principales incentivos es precisamente ése: que una vez desarrollado un proyecto con visión holística y de largo alcance puede servir como un horizonte de referencia lejano en el tiempo para que pueda seguir siendo un plan estratégico de desarrollo del portal vigente a lo largo de muchos años.

\section{REFERENCIAS BIBLIOGRÁFICAS}

Todas las referencias electrónicas han sido verificadas como existentes en septiembre 2011.

Albornoz, L.A. y Herschmann, M. 2007. "Balance de un proceso iberoamericano. Los observatorios de información, comunicación y cultura”. En: Telos, núm. 72. Disponible en: http://sociedadinformacion.fundacion.telefonica.com/telos/articuloperspectiva.asp@ idarticulo $=3 \& \mathrm{rev}=72 . \mathrm{htm}$ 
Apps, Ann \& McIntire, Ross .2000. "Dublin Core Metadata for Electronic Journals “ En: Lecture Notes in Computer Science, Research and Advanced Technology for Digital Libraries. Volumen 1923, 2000, pp. 93-102, DOI: 10.1007/3-540-45268-0_9.

Bolisani, Ettore. 2008. "Building the Knowledge Society on the Internet: Sharing and Exchanging Knowledge in Networked Environments". IGI Global, 2008. 440 p. ISBN: 1599048167.

Business Dictionary. 2011. Webfinance, Inc. Disponible en: http:// www.businessdictionary.com/definition/vertical-portal.html

Castañeda de León, L.M. 2006. "Observatorio virtual: más que un portal”. En: "Entér@te en-línea”. UNAM. Dirección General de Servicios de Cómputo Académico. Año 5, Núm. 46, febrero de 2006. Diponible en: http://www.enterate.unam.mx/Articulos/2006/febrero/observa.htm

Chauvel, D. \& Despres, Ch. (Eds.) 1990. Wiig, K. (Aut.) "Knowledge Management: An Emerging Discipline with a Long History". Capítulo en libro "Knowledge Management". Disponible en: http://www.krii.com/downloads/km_emerg_discipl.pdf

Dappert, Angela \& Enders, Markus. 2008. "Using METS, PREMIS and MODS for Archiving eJournals”. En: D-Lib Magazine. September/ October 2008. vol. 14 núm. 9/10. ISSN: 1082-9873. Disponible en: http://www.dlib.org/dlib/september08/dappert/09dappert.html

Garratt, B. 1987. “The Learning Organization”. Fontana Press. 144 p. ISBN: 0006369235.

IDF - International DOI Foundation. 2010. "The Digital Object Identifier (DOI) System”. Sitio oficial del proyecto. Disponible en: http:// www.doi.org/

Ives, W., Torrey, B., \& Gordon, Cindy. 1997. "Knowledge Management: An Emerging Discipline with a Long History”. En Journal of Knowledge Management, Volumen: 1, núm.: 4, pp. 269-274. ISSN: 13673270. DOI: 10.1108/EUM0000000004598

IVOA. International Virtual Observatory Alliance. 2007. Disponible en: http://www.ivoa.net/

Maiorano, J.L. 2003 "Los observatorios de derechos humanos como instrumento de fortalecimiento de la sociedad civil". En: Revista Probidad, núm. 24, septiembre de 2003.

Melero, Remedios. 2005. "Significado del acceso abierto (open-access) a las publicaciones científicas: definición, recursos, copyright e impacto". En: El profesional de la información. Vol. 14, num. 4, pp. 255-266. Disponible en: http://www.elprofesionaldelainformacion.com/contenidos/2005/julio/3.pdf

"Mobile Web Best Practices 1.0" "Basic Guidelines, W3C Proposed Recommendation”. 2006. Disponible en: http://www.w3.org/ TR/2006/PR-mobile-bp-20061102/ 
Wiig, K. 1996. "Knowledge Management: Where did it come from and where will it go?”. En: Expert Systems With Applications. Vol. 13, núm. 1. pp. 1-14. Elsevier Science. Disponible en: http:// kplab.tuke.sk/hardwiki-mz/images/3/3f/Clanok5.pdf

W3C - World Wide Web Consortium. 2011. "HTML5 Edition for Web Authors revision 1.4626: a vocabulary and associated API's for HTML and XHTML". W3C Working Draft 13 January 2011. Disponible en: http://www.w3.org/TR/html5/author/

Web Design Group. 2006. "Standards for HTML Authoring for the World Wide Web", October 2006. W3C - World Wide Web Consortium. Disponible en: http://www.htmlhelp.com/design/standards.html\#Validation

Zeldman, Jeffrey. 2006. "Designing with Web Standards: Voices That Matters". 2nd Edition. Berkeley, CA: New Riders. 2006. ISBN: 0$321-38555-1$ 